\title{
Negotiating a healthy body in old age: preventive home visits and biopolitics
}

\author{
By LENE OTTO*
}

\begin{abstract}
The study discussed in this article sheds light on how a specific publichealth policy, the preventive home visit (PHV) aimed at senior citizens, is implemented at the local level in Denmark. Empirically the article calls attention to what is actually going on in a preventive practice, based on participant observations, interviews and ten years' worth of visitation records. ${ }^{1}$ Theoretically, the article applies a Foucauldian biopolitical approach that understands the visits as an implementation of the active ageing scheme, as the notion of prevention is practised as a continuous process, which is utilised to train people's gazes and sensitivity, and teach them to recognise "activity" as closely linked to future well-being and longevity. An important finding is that the intervention is not normalising

*Lene Otto, Department of Ethnology and Center for Healthy Ageing, University of Copenhagen, Copenhagen, Denmark

${ }^{1}$ The study is part of the work done by the research group "Health in Everyday Life - HEL". This group explores the impact of activity-focused goals on midlife and elderly citizens in various preventive and health-promotion arenas, as well as the ways in which these become domesticated in the lives of the elderly. The group is part of the Centre for Healthy Ageing (CEHA) at the University of Copenhagen, Denmark. As a group, we combine ethnographic fieldwork, historical analysis and readings of policy texts in order to uncover the intertwinement of cultural practices, narratives, discourses and experiences.
\end{abstract}


International Journal of Ageing and Later Life

in a deterministic way but rather negotiable. Even though the home visitors represent a health regimen where activity is interpreted as bodily exercise, they try to avoid the tendency to prescribe for older people. Rather than prevention in the strict sense, it seems to be a health promotion strategy that encourages older people to articulate their needs. The meeting between the health visitor and the older person is characterised by conversations and negotiations about health, autonomy and bodily experiences.

Keywords: preventive home visits, Foucauldian gerontology, active ageing, health promotion, biopolitics, health advisors.

\section{Background}

In an ageing world, biopolitics interact with life in new ways. It is widely recognised that expectations about the life course are changing as demography changes. The prevailing cultural meaning of ageing today is informed by dominant values of remaining energetic socially, intellectually and physically (Neilson 2006). A new generation of old people is working longer, have more resources and may look forward to many healthy active years, but this requires prevention and health promotion interventions for the younger elderly. Practices and discourses such as "anti-ageing," "active ageing" and "healthy ageing" can be seen as ways of managing the population and crafting the experience of being elder, thereby producing active, healthy and long-living subjects. The concept of active ageing is well rehearsed as part of a "new paradigm" of ageing which aims to displace the old "decline and loss paradigm" (Holstein and Minkler 2007), but on the other hand delegates the responsibility for the quality of life in old age to the senior citizens themselves. Overall, healthy ageing and the concept of "good old age" are gradually becoming more connected to activity, mental as well as physical. Being physically active is promoted at all levels from international policy documents ${ }^{2}$ to national health policy programmes and provisions for health promotion. In contrast to "healthy ageing" that points

\footnotetext{
${ }^{2}$ See, for example, WHO: A Policy Framework. The word "active" refers to continuing participation in social, economic, cultural, spiritual and civic affairs, not just the ability to be physically active or to participate in the labour force. Often it is instrumentalised as the correct dose of physical activity.
} 
to the biological body or "productive ageing," which limits itself to economy, activity as a concept does not limit itself to a particular sphere (Davey 2002; Moody 2001).

\section{Outline of the article}

The article starts by setting the preventive home visit (PHV) model in a broader old age health policy context in Denmark, emphasising dilemmas and changes. Then the article examines "activity" as both a discourse and an embodied experience, and looks at its relation to the emergence of the preventive health visit as a specific health-promotion intervention aimed at older people. Next, some qualitative cases from the study are presented which draws on empirical data from an archive study and an ethnographic participant observation study of the micro-practices of health promotion in people's own homes. The focus is not on people's perceptions as formulated in interviews but on the practice, for example, the negotiation between the expert and the elderly, to show what happens between the preventive staff and the senior citizens during a typical meeting; finally, whether it makes sense to explain this kind of prevention as a form of biopolitics is discussed, in which new obligations and identities are created.

\section{Active ageing in Denmark}

Care for the elderly in Denmark is mainly organised, financed and provided by the public sector. As a welfare society, it is generally characterised by the availability of extensive public services. In its overarching policy goals, Danish eldercare still adheres to the principles of universalism, formalisation and professionalisation of care (Rostgaard 2011). Under a legislative framework established by the central government, local authorities deliver different kinds of eldercare services. In recent years, the demographic tendencies have been called upon as a threat to the welfare society because of a continuing increase in the proportion and absolute amount of older people, particularly those aged 85 and over. In response to the higher costs anticipated for institutional care, the objective of eldercare has been formulated as "ageing in place" or "remaining as 
International Journal of Ageing and Later Life

long as possible in their own homes," as this policy is termed in Denmark (Danish Elderly Commission 1980).

\section{Citizen-oriented health promotion}

It is seen as important to meet the needs of the elderly with diverse healthrelated interventions. The 2007 Danish municipal reform challenged Danish municipalities to focus on health in new ways and with greater force, for example, citizen-oriented health promotion which aims at creating, shaping and facilitating certain ways of ageing healthy. Reforms in Danish welfare tend to be dualistic though, on the one hand, politicians argue for voluntariness and responsibility for own health; different municipal settings where citizen-oriented health promotion activities take place are offered if people are motivated. On the other hand, new health promotion initiatives are launched where the municipal health professionals target citizens in their own homes; they are offered individual life style change training. Therefore, the municipalities employ health ambassadors and exercise coordinators offering health tests and health interviews and they are even expected to make unsolicited phone calls to people who live unhealthy lives, to offer them various courses.

Another proactive societal action is the use of PHVs targeting community-dwelling older persons. The purpose of PHV is to promote overall health and wellbeing in old age, to identify people at risk for health problems, to prevent further decline, to enhance the possibility for the individual to maintain activity and participation, to be in control of everyday life, and to experience life satisfaction. PHVs have attracted political attention, and, in Denmark since 1998, such activities are mandatory by law. Every municipality in Denmark has been required to offer annual PHVs to citizens aged 75 years or older. The Act no. 1117 of 20 December 1995 on preventive home visits to older people states: "The purpose of the Act is meant to strengthen preventive and health-promoting activities targeted at older people." And further, that the aim of the home-visit scheme "is to support older people's self-care and to aid them in utilising their own resources optimally." About $80 \%$ of all Danish senior citizens regularly receive these visits to their homes from health-promotion staff, known as a "home visitor" or a "health advisor." 


\section{The PHV}

PHVs may be categorised as "health promotion" since the health advisors are supposed to support, advise and counsel via conversations, and they do not have a mandate to diagnose, prescribe medication or refer the senior citizens to specialist doctors. PHVs are an offering that an older person may choose to accept or refuse, and the individual who accepts can decide exactly what he or she wants to reveal or discuss - the home-visit interview is supposed to focus on the senior citizen's general needs, but always on the older person's terms. These visits are usually carried out by trained nurses and address both health and social issues, although the exact details of local programmes have been left fairly flexible and the use of standardised assessment tools is a non-compulsory option. As a result of this flexibility, there has been a great deal of variability among municipalities with regard to the visits' characteristics, that is, what components are included and how much emphasis is placed on medical concerns, Everywhere the PHV addresses the biological process as well as various cultural, institutional, social and everyday ways of handling ageing; but more broadly, PHVs attend to the general biopolitical problem of "lifestyle." 3

From prevention of functional decline to promotion of active ageing When the Danish law was adopted in 1995, the main objective was to prevent functional decline, which is understood as a medical condition that characterises the biological ageing process. But our study shows that the new conceptions of active ageing seem to be informing the contemporary practices of the preventive home-visit programme.

Active ageing is seen as a possible solution to the demographic challenge, but it is strongly contested whether activity is to be translated to social participation or exercise. Generally, there is an explicit focus on

\footnotetext{
${ }^{3}$ I use the term "biopolitics" to refer to the various policy initiatives that seek to manage and affect people's biological bodies as well as the preventive and healthpromotion practices that are established around ageing to encourage older individuals to change their lifestyles and manage their conditions. Among them, and the focus of attention in this study, is the PHV.
} 
International Journal of Ageing and Later Life

physical activity in public health in Denmark, which is a relatively recent phenomenon on the political agenda; it was not evident until the 1990s, condensed into the Danish acronym KRAM (diet, smoking, alcohol and exercise). Since 2005, the benefit of performing exercise has become one of the official pieces of health advice given to the Danish population. Officially, physical activity is recommended for the prevention, treatment and rehabilitation of heart disease, diabetes, obesity, cancer, respiratory diseases, muscle and skeletal disorders, rheumatic conditions, epilepsy, incontinence and mental disorders. This focus on physical activity and exercise indicates that regular physical training is now considered to be one of the key components of good health, liberated from the obesity problem. And now, it has also found its way into eldercare. With the elderly as a new user-group in health promotion, exercising is promoted as a way to prevent or postpone frailty and functional decline. Current public-health messages promote domestic and other daily-lifestyle physical activity as well as more facility-based, structured exercise for older people. Here, the home visit becomes important as a kind of what one may call a "motivation technology."

\section{Pro-active ageing}

PHVs targeting community-dwelling older persons represent one example of proactive societal action. The purpose of PHV is to promote overall health and wellbeing in old age, to identify people at risk for health problems, to prevent further decline, to enhance the possibility for the individual to maintain activity and participation, to be in control of everyday life, and to experience life satisfaction. Even though the Danish welfare society put a great deal of trust into technological innovations for monitoring different health conditions and mediating contact between health professionals and senior citizens, "a social innovation" like the PHV is also considered useful, especially in relation to new conceptions of pro-active ageing. In this sense, "pro-active" means engaging in exercise and activities that are promoted as a means to enhance well-being, rather than to help the older person recognise how to handle life's unavoidable changes appropriately, that is, to prevent further decline. A report by a Danish Elder organisation (AgeForum 2009) stresses that "Research and development projects have documented that physical performance and 
functional ability can be improved even at very old ages. We cannot prevent death, but perhaps postpone it, not merely to add years to life, but also with a view to preserving independence as long as possible" (21). The key word here is "improve": the idea is that ageing is not a process of decline, but instead a process of potential development and growth In fact, older people have become much more physically active in recent years. According to the study "Danish exercise and sports habits" (Pilgaard 2007), people in their 70s are just as active as people in their 20 s. And $62 \%$ of the 60 - to 69 -year-olds exercise - more than any other adult age group - and the proportion has been increasing in recent years. In 2004, it was only half of the age group, and in 1987 only $30 \%$.

In summary, the preventive home-visit scheme is defined as visits to elderly people who live independently; the visits are aimed at conducting a multidimensional medical, functional, psychosocial and environmental evaluation of their problems and resources. The visits should be personalised, lead to concrete interventions, and be followed up. The health areas assessed should derive from a broad perspective and include social, psychological, and medical aspects. The direct approach to each individual citizen, which is the foundation of the PHV, also enables local authorities to establish contact with people who they otherwise would not have had any interaction with. In other words, the home-visit scheme gives politicians and municipal health authorities a rare insight into senior citizens' lives; thus, they are uniquely enabled to tailor initiatives and activities to the older population's needs.

To date, no studies have assessed the more qualitative aspects of the home visits, such as improved well-being, sense of vitality and feelings of inclusion; this may be because such factors could never be controlled in a way that would meet the requirements of randomised, controlled trials, but several quantitative public-health studies confirm that, despite a lack of traditional intervention and mandate, these home visits have a good effect with regard to, for example, preventing falling accidents and minimising or delaying the need to move an elderly person into a nursing home (Hendriksen 1989; Vass 2010). Studies have reported that preventive visits have led to 80-year-olds having significantly higher functional levels, significantly fewer nursing-home days, and that neither effect was significant in the 75-year-old cohort, nor were there any apparent effects 
International Journal of Ageing and Later Life

on survival (Vass 2010). So, this kind of intervention has proved to be a suitable instrument for maintaining elderly people's (80 years old and over) autonomy, independence and functional ability, and in allowing them to remain in their own homes as long as possible. In our study, we ask what happens during the home visits that make them so apparently successful?

\section{Theoretical approaches}

The Dutch philosopher Annemarie Mol's work on care has inspired my understanding of the practice of PHV. I argue, that home visits in practice can be understood as a negotiated, symmetrical and shared care process equivalent to the logic of care (Mol 2008) that is characterised by health providers who take into consideration the user's preferences, resources and networks available to them. The care process is open-ended health negotiations that are linked to a citizen's everyday life, characterised by shared doctoring (Mol 2008) and tinkering (Mol 2010) as on-going adjustments to the care process; in contrast to the logic of choice, a form of care that presents different actions or treatments to choose between.

The article also examines if the home visits can be seen as an enactment of a "politics of active ageing," and accordingly as a bio-political intervention in which elderly citizens are encouraged to be active. Michel Foucault introduced biopolitics as an umbrella term for the ways in which the state and other authorities assume the task of managing citizens' everyday lives by introducing systems for education, welfare, health care and so on. Foucault argues that the coercive power of sovereignty has historically given way to a modern, decentred form of governmental rationality that produces subjects who act in accordance with forms of political paradigm and power. Thus, biopower is understood as a web of cultural practices. In Foucault's work, a recurring theme is that the truths that are produced in the name of science also change the human as a subject when they are made available as concrete practices and techniques. Through activities like life style change and exercise, the body becomes an object that the subject is faced with and must do something with. In Foucault's understanding, this objectification process is negative because it implies control, but it may also be positive because the objectification 
creates room for a new identity, a new subject. Through this, a new and different self-consciousness is created, and the human as a subject is changed.

In line with that, I understand contemporary biopolitics in terms of the formation of experience; the expansion of forces and capacities. The sociologist Claire Blencowe formulates the same view as follows:

\begin{abstract}
The history of biopolitics is not just about the development of certain political institutions or the political uses and abuses of biological science. It is also about a historical reconstitution of experience, of the organization of meaning, of what matters, of authority and games of truth, such that immanent processes, embodiments and manifestations of vitality or intensity become salient in the formation of perception and judgment (Blencowe 2012: 5).
\end{abstract}

By emphasising the experiential dimensions of biopolitics, I want to take Foucault's notion of biopolitics seriously, seeing medical paradigms/ regimes not only as repressive but also to consider the potential positivity, appeal and productiveness of the biopolitical promotion of active ageing and physical activity. Then my theoretical question is: if official exercise recommendations are offered as a discursive practice, would a ritual with a corresponding language allow the body's capabilities to be explored and experienced in new ways? The hypothesis is that the ageing body becomes a biopolitical target when health promotion operates as a continuous process, which is utilised to train people's gazes and sensitivity, and teach them to recognise "activity" as closely linked to future well-being and longevity. It is evident that this theoretical position is in opposition to the widespread medicalisation hypothesis in which science and professional care is seen primarily as social control and discipline, as well as to a more instinctive phenomenological view wherein the authentic body and its sensitivity and experiences is considered to be independent of these forms of practices.

It is an explicit objective of the study to engage with the methodological and theoretical challenge on how to study the connections between biopolitical (and biomedical) knowledge and everyday experience whilst avoiding dualistic and deterministic ontologies. How do we explore and explain the complex and contradictory connections between what is 
International Journal of Ageing and Later Life

experienced as biological processes and the mechanisms of governance in today's ageing societies?

\section{Foucauldian gerontology}

Some answers to that question have been provided by the so-called "Foucauldian gerontology," which attempts to understand how ageing is socially constructed by discourses used by professions and disciplines in order to control and regulate the experiences of older people, and to legitimise the powerful narratives afforded to age by such groups (Powell \& Wahidin 2006). Using a Foucauldian perspective, several scholars have stressed that health and active-ageing discourses must be understood as forms of domination and objectification (Stott 1981; Katz 1996; Powell \& Biggs 2000). They argue that, both historically and contemporaneously, the identities of elderly people and old age have been constructed through experts' discourses of "decay" and "deterioration" in order to intensify the regulation of older people. Even when we seem to be moving away from fixed and static conceptualisations of "deterioration" - when older people are no longer met with "it's your age," and when older people's identities are constructed through notions of active and healthy ageing - such discourses are often perceived as technologies of regulation and collective control (Katz 2000). New technologies and care discourses within the activeageing paradigm are criticised for claiming to provide choice and reduce the limitations associated with ageing whilst they actually represent an increase in professional control. Hence, social practices are revealed to be products of power rather than empowering. Accordingly, the term "biopolitics" implies that life itself is situated within structures of power and becomes a political object as soon as the state acts on its interest to maintain the survival, strength and well-being of the population, that is, to preserve it from its opposite - namely, death.

\section{Experience}

In contrast, in this study I have been less interested in demonstrating the cruelty or fallacy of active ageing as a political discourse or institution; rather, I seek to elucidate active ageing in terms of the expansion of forces, capacities and experiences of embodied pleasures, affects, capacities and 
knowledge. The concept of experience, with its connotations of individual psychology, may seem out of place in a biopolitical framework because the exploration of experience is generally associated with an ethos of humanism, an emphasis on the importance of the subject and its emotions, and qualitative methodologies, ethnography and understanding. And, with a few exceptions (Blencowe 2012; O'Leary 2008), Foucault is seldom associated with the concept of experience. However, contrary to the common view of Foucault as a theorist who reduces the affective and embodied to rules about the formation of linguistic discourse, Claire Blencowe argues that Foucault's analysis of discourse, rationality and rhetoric is wholly intertwined with an analytic of affect and embodiment of passions that grip a person for no reason, have no origins and are mobile without being directed towards a given point (2012: 68). In the same vein, Timothy O'Leary argues that Foucault's work continuously strives to understand and disentangle the connections between forms of experience and forms of knowledge; between subjectivity and truth. ${ }^{4}$ I understand Foucault's critical history of thought merely as the history of the forms of our experience and what constitutes the human being as a subject (Foucault 1976). The idea that our experience - in the everyday sense of the term - is entangled with forms of knowledge, power and relations to the self that are historically singular is theoretically useful when trying to understand how discourses constitute new forms of bodily experience and new forms of desire. We must study the forms of experience through an analysis of practices, for example, discourses as embodied in preventive practices. To speak about the experience of activity is then to speak about the forms of consciousness, sensibility, practical engagement and scientific knowledge that take "activity" as their object.

In accordance with the abovementioned scholars, I read Foucault's analysis of biopolitics as a history of affective investments, embodied subjectivities and structures of experience. Foucault did not see experience as foundational to knowledge, but rather the other way around: that

\footnotetext{
${ }^{4}$ This is precisely what Foucault does in his histories of madness, the prison and sexuality. He did not seek the a priori of experience; rather, he historicised both the $a$ priori and experience by identifying singular forms of experience and desire and working towards their transformation.
} 
International Journal of Ageing and Later Life

knowledge is constitutive of subjects through experiences. He sees experience itself, the process of experiencing - perceiving, seeing, desiring, feeling, knowing, being the subject - as something that is shaped historically. Those capacities are formed and transformed by biopolitical means, not prior to them. Thus, I argue that understanding older people's own experience is important - not as a return to a mute and original bodily experience, but rather as the constitution or formation of experience.

\section{Research questions}

Rather than speculative reflections about the possible implications of ageing discourses, I ask how the process of motivation, mobilisation or interpellation $^{5}$ is done in practice when it takes the form of PHVs. Accordingly, the PHV study was designed as a qualitative study to explore the experiences of older men and women who were subjected to municipal health promotion initiatives. We were interested in the perceptions and routines, but the study was not meant to evaluate the efficacy of home visits. Thus, the study is explicating how the care process occurs and at the same time using theoretical concepts related to the governance of ageing. The emphasis on negotiations is a consequence of the theoretical standpoint that people's experiences and conceptions; what people themselves think and desire are intertwined with expert discourses, concepts and devices. The key question is how people's experiences of their body and well-being are interwoven with a particular health regime's scientific concepts and devices.

\section{Method, design and analysis}

The data that formed the basis of this article were derived from: I) an analysis of visitation records $(n=52)$ kept by a group of municipal health visitors in the period 1995-2007; and from II) a participant observation study during 13 home visits and additional interviews with the same elderly single-handed, as well as two focus group interviews with four

\footnotetext{
${ }^{5}$ Interpellation is the process by which a person recognises himself as belonging to a particular identity (first coined by Louis Althusser 1970).
} 
health advisors, and some additional informal interviews/conversations with non-users whom we met in the local community.

I) The Center for Healthy Ageing got access to the records when the Frederiksberg municipality did an internal reorganisation and discarded older material concerning home visits. The records were reviewed and coded for themes. Three key themes emerged from this reanalysis: exercise, motivation, and bodily appearance.

II) In order not to take the written assessments at face value, we did ethnographic fieldwork to explore how the visits are practiced and perceived by users and professionals. During our fieldwork observations, it turned out that the visits took the form of a mixture of care, health promotion and evaluation. Following the observations, two focus group interviews were conducted with a group of health visitors at their office. The interviews took place during the group's regular meetings, which we were invited to participate in. As a result, all of the health advisors in the municipality contributed to the study, not as individual informants but as part of a professional group in either of the two focus group interviews. In parallel, the elderly were interviewed individually $(n=20)$ in their homes with interviews ranging from 45 to 90 minutes. All respondents gave informed consent. The interviews were tape-recorded and transcribed verbatim and analysed after being read line-by-line to gain a holistic overview and then re-read and coded. This process was reflexive, and as new codes and themes emerged, the interviews were recoded.

\section{The study}

Although policy documents about active ageing generally emphasise continuing labour and postponing retirement, the meaning of activity in the PHVs, like in prevention and health promotion in general, seems to revolve around the body

\section{Records}

The new general ambition to enhancement, improvement, development and growth - even in old age - is also reflected in the visitation records we analysed. During the ten years of notes that we had access to, we noticed a change in how ageing was perceived. In the first records (1995-2000), the 
International Journal of Ageing and Later Life

older persons were described physically, mentally and socially; old age was clearly perceived as a stage of life characterised by disease and maladies. In accordance with this perception, the stated purpose of the home visit was to keep a close eye on the "five Ds": Dementia, Depression, Drugs, Drinking and Deliriousness. In the newer visitation records (20012007), there is more focus on possible developments and even on future action plans - and exercise.

In practice, at least according to the visitation records, activity is associated with physical health and functionality, which is translated as training the body. Among the eight obligations listed in "The preventive home visitor education programme" from 1999 is that a health visitor must "stress the importance of physical activity and stimulate the municipality to facilitate participation in physical activities through convenient transportation to rehabilitation and sports for older people" (Vass 2010: 53). And it seems as though the health visitors did indeed fulfil this obligation. For example, it is noted in the journal if an elderly person is "very motivated for training." There is no column for this provided in the journal, but notes about training are made in the margins: "exercise, walking, goes on outings."

According to these notes, the health advisors motivate and encourage older citizens to start or resume exercising; it seems like a gentle pressure is put on them. The impression is that daily exercise by walking, Nordic walking or gymnastics is an implicit criterion for healthy ageing. The level of activity may be assessed as: "active, outgoing. Agile, in great shape" whilst in other circumstances, it is noted: "encouraged to increase physical activity - is very responsive." In several cases, the health advisors note that they distributed pamphlets to the older people about exercise classes in the local area. Also, some comments are made about body weight and general appearance, which may seem rather normative: "a little overweight but well groomed."

In the visitation records, we can also occasionally see that the health advisors do not necessarily agree on the role and meaning of physical activity in the elderly person's life, that is, whether it is an end in itself or a means to something else. For example, should an older man get help to put on his support stockings in order to be able to go outside, or should he be encouraged to exercise so he can gradually do it himself? First, 
there is a message from one health advisor to another, saying that she must be sure to help the man with his stockings. But the other health advisor answers: "It is not about the stockings but about exercises that can loosen up tight muscles and tendons, then the citizen will be able to put on normal socks by himself - I have referred him to a physiotherapist about this."

\section{Observations}

Once the health advisor has entered the citizen's home, the older person usually sets the agenda and pace of the visit. Almost all of them had prepared a coffee tray and gave a short update on their lives since the health advisor's last visit, possibly half a year ago (according to the law, the elderly are offered a PHV twice a year). These updates included various health topics, such as the status of a diabetes regulation or a prostate or weight problem. But when they summed up their health situations, the older citizens expanded the idea of health to include a range of social factors like family, friendships, holidays or financial situations. The cosy atmosphere of most of the visits did not preclude professional health advising from being carried out, but it seemed surprisingly symmetrical when negotiating for individual, possible and meaningful care and personal resources. An example of this is Mrs Stein (age 81), who gave up on rehabilitation exercise after a broken hip. She could not reach her busy doctor, was in pain and felt confused and unable to navigate her way through public-health services, phone numbers, opening hours and constant offers of activity in the sheltered senior citizens' building where she lived. When Mrs Stein finished telling the health advisor about all of this, she was tired and crying. The health advisor responded by pointing out and acknowledging Mrs Stein's stubbornness because this was needed in order to exercise effectively. She then managed to contact Mrs Stein's doctor and have her referred for another round of rehabilitative exercise with a physiotherapist. In these interactions, the health advisor searched for and vocalised the senior citizens' individual talents, thus practicing the idea of empowerment by sourcing knowledge and specifically utilising a strategy to enhance and reinforce the citizen's already existent personal resources and abilities. 
International Journal of Ageing and Later Life

It seemed that most citizens in the study were willing to and comfortable with entering these health negotiations and planning personal ways of coping with their ageing bodies, their possibilities and limitations. As the health advisors all had extensive knowledge of the part of Copenhagen where the fieldwork took place, they were familiar with a lot of the conditions and obstacles that the older citizens met during their daily lives. This probably made the design of individual care and health promotion easier than it would be at, for example, a county hospital. In the following, we will meet 81-year-old Mr Thomsen who has not been out of his flat for more than a month due to a lot of snow and ice in the streets. Other health professionals have presented him with the choice of buying an exercise bike so he can stay in shape or leave it and lose muscle strength; a logic of choice ( $\mathrm{Mol} 2008$ ) or an asymmetric care rationale where the health professional is an expert who presents possible solutions. When the health advisor and Mr Thomsen discuss his exercise program, it turns out Mr Thomsen bought the bicycle but is bored with riding it in his living room without getting anywhere so he quit the exercise. He much prefers to resume his daily walks in the city. To encourage him to do that, the health advisor pointed out a nearby store where special non-slip soles could be bought for his shoes, and she arranged for neighbours to buy them for Mr Thomsen.

In another case, the health advisor planned a detailed walking route that avoided traffic lights for 99-year-old, almost-blind Mrs Nielsen so that she would not give up the walks, despite her daughter's protests. This is another example of willingness to partake in a shared process of negotiating possible and meaningful health promotion. Mrs Nielsen is keen on exercising but her weekly walks in the neighbourhood with a group of old citizens arranged by the municipal health department are troubled by the many traffic lights which are difficult for her to interpret. Consequently, Mrs Nielsen's daughter is urging her to give up the risky walks. Mrs Nielsen and the health advisor enter into a detailed process of negotiating Mrs Nielsen's route, which crossings to avoid, when to stay behind and how to exercise on her own until the rest of the walking group returns on the route.

In the following example of care practiced as negotiation, we will again meet 81-year-old Mrs Stein who suffers from rheumatism in both hands 
and was widowed last year: Mrs Stein cannot cook for herself and besides, has lost interest in food, she says. During the home visit, the health advisor engages with Mrs Stein in uncovering her eating patterns and preferences. It turns out that Mrs Stein actually still loves food, though not the food she was asked to choose from a caterer of readymade meals when she was diagnosed with being underweight six months ago. Mrs Stein's favourite food turns out to be seafood and the health advisor arranges with Mrs Stein, her daughter and her home help that shopping and making seafood sandwiches to keep wrapped up in the fridge be put into a weekly schedule. This shared process of caring for Mrs Stein's weight problem solves a serious health problem through inclusion of all practicalities, preferences and network available and not only nutritional and medical aspects of Mrs Stein's underweight.

Summing up, this way of negotiating health issues while including resources, relations and preferences of the citizen is an established practice among the health advisors in our study. They seem to take on a more active role, not only informing of and co-ordinating medical services, but tracking care solutions that are attuned with the old citizens' individual daily lives. But of course, the negotiations sometimes seemed asymmetrical: the final example of this apparent discrepancy between an institutionalised view and an older person's view on individual autonomy is that of the aforementioned Mrs Stein. She requested help getting washed and dressed in the mornings, but the health advisor was reluctant; the goal of recovery and regaining autonomy is being able to do everyday chores on one's own. Mrs Stein complained that, when she was in the hospital with her broken hip, the staff was already urging her to wash and dress herself - even though this made her so tired that she would have to take a nap afterwards. Back in Mrs Stein's flat, this pattern continued with the home visitor, who repeated the suggestion that she wash and dress on her own. But at the same time, Mrs Stein was urged to participate in the various social arrangements and training offered at the sheltered housing where she lives. She would like to get out and meet people, but she is always too tired for it. This topic was discussed back and forth between Mrs Stein and the health advisor. The health advisor moderated her point by saying: "Because - it's like this: if you get dressed and then it's like, Wooh, now I'm tired for two hours, then it's something you 
International Journal of Ageing and Later Life

could discuss with your home help." However, Mrs Stein agreed that she would really try to do these things on her own, and the health advisor said: "But that is so good because that is of course the only way you get back your energy," and Mrs Stein repeated but complained: "Well, then, that is the only way I can get back my energy. I think ... but I get so tired. And then I fall asleep on the couch and then I can't take part in any of the arrangements downstairs."

\section{Autonomy and resistance}

During a home visit, the work of care is occasionally challenged or even resisted. For example, more than anything, Mr Holten (age 78) preferred to sit in his good chair whilst Mrs Holten did all the housework, drove the car, kept the flat and the summerhouse, and maintained all the social relationships. When the health advisor urged Mr Holten to increase his level of activity and go for a daily walk, he frowned and replied: I'm fine as it is!!

In another example of an attempted but unsuccessful health negotiation, we shall meet Mr and Mrs Havemann, an old couple who has been together for many years. The couple has an unhealthy lifestyle; they both smoke a lot, sometimes substitute a meal with alcohol and Mrs Havemann has had a potentially life threatening medical condition. During a visit in their home, the health advisor suggests that the couple prepare some vegetables to eat with their dinner and maybe cut down on sauce and potatoes instead. Mr Havemann is not able to move well or do household chores but the couple has a well-known ritual of Mr Havemann peeling potatoes - the one thing he can do - and Mrs Havemann frying the meat and making the sauce every evening. When presented to the health promoting suggestion of adjusting their eating habits, Mrs Havemann is upset: All this trendy new food, she says, they can stuff it! Thus totally denying to enter any negotiation or shared care process that the health advisor tries to initiate. The problem here is not that $\mathrm{Mr}$ and Mrs Havemann do not want a long and healthy life together but rather that when presented with a possible adjustment, the couple experiences an either-or choice between two contradictions, health and a treasured daily ritual. Given this choice, Mrs Havemann can only reject the idea of eating healthier as she cannot possibly reject the couple's shared daily cooking ritual. This is an example where the citizen never 
enters the negotiation but perceives the situation as choices of already fixed solutions, maybe because they are presented as such. Consequently, a logic of choice characterises the home visit; the choices available and their potential drawbacks are not meaningful to the Havemanns so they end up choosing the well-known daily life in the flat where the advise of health campaigns, doctors and advisors have no power.

Both Mr Holten and Mr Havemann probably knew that the advice they got would do them good, at least in a strict medical way, so why did they reject it so clearly? They both accepted the health-promoting visit, which seems to indicate a certain interest in a care of the self and still they were upset by the health-promoting suggestions they got. In the cases where the citizens refused to partake in a health negotiation with the health advisor, or even to receive a home visit at all, something else other than unwillingness to stay or become healthy was probably at stake. I will argue that they had the same wish for health as the other citizens but another perception of the home visits: These citizens might anticipate or experience the home visits in the sense of an asymmetrical care rationale, where they are met by health choices of fixed, already negotiated solutions, but there is also something else at stake, different perceptions of autonomy; statements by three of the seven individually recruited informants whom we interviewed support this view. These citizens had rejected the home visits and claimed a health advisor's visit to be potentially dangerous in terms of losing one's autonomy through being told to eat or act differently and through being unwillingly moved to a nursing home. In the 13 participant observation cases, we did not meet any citizens who spoke of the visits as representing a risk though this could be due to a bias caused by feeling grateful that somebody cares for your health, even though the care in this case is formalised, public and paid for (Lewinter 2008). The independently recruited citizens were all healthy in a medical sense and had no or little contact with their GP's but the mere fact or thought of the welfare state being in one's home through the health advisor's visit might contribute to a negative sense of being urged to live differently even though you are a mature adult with own, well established practices.

In the municipality in our study, some $60 \%$ of aged citizens reject the home visits and in the study itself, half of the independently recruited 
International Journal of Ageing and Later Life

citizens claim they would never enter the home visit program. This indicates it can be a problem that a public health authority visits the private home and has points of view as to the citizens' individual possibilities of staying autonomous, his or her levels of health and needs to change her or his habits. But not only the mere visit or the anticipation of it as a treatment rather than negotiation contributes to rejecting the home visit. Some citizens' reactions to health promoting suggestions that called for a retreating and disarmingly cheerful behaviour from the health advisors indicate that there is a thin and not vocalised line defining how far the welfare state may actually go in order to promote health in the privacy of the citizens' homes and make them more dependent on other people or artefacts. Dependency is generally seen as a negative outcome. On the other hand, one could argue with Kittay that dependency is a fundamental aspect of human life course (Kittay in Fine and Glendinning 2005: 607). However, different times and societies in history influence the way dependency is understood and in advanced liberal democracies, a promoted ideal of the autonomous individual able to act and navigate completely independently in society collides with acknowledging dependency as a basic aspect of some stages in life (Fine and Glendinning 2005: 613). This ideal might well be an important factor too in rejection of the home visits and also emphasises that health care and self-care should not only be understood as related to body and psyche but also as tightly interwoven with contemporary discourses of how to be a successful old person and with daily lives, social relations, habits and understandings of autonomy (Biggs 2001).

\section{Conclusion and reflections}

In the article, it was unveiled how PHVs are part of more widespread welfare changes, and how they are connected to discourses on healthy ageing and affects how the PHV is conducted. Although it is not directly organised as an implementation of active ageing, the PVH works as a means to mobilise the active citizen. Although policy documents about active ageing generally emphasise continuing labour and postponing retirement, the meaning of activity in prevention and health promotion seems to revolve around the body. In practice - at least in the cases 
discussed in this article - the concept is associated with physical health and functionality. When put into practice in preventive interventions and care relations such as the PHV, activity is habitually translated as training the body. Activity is mostly interpreted as physical exercise; that is, making exercise an integral part of an older person's everyday life. It is evident that training and exercise are a recurring theme during the home visit. It is also clear that health is promoted as and primarily associated with bodily activity. Our observations and the visitation records both indicate that activity is the main issue when the preventive staffs visit individual older people. During the observations it also soon became evident that the body's functionality and capability was in focus and that it was negotiated during the visits. The staff tried hard to build a relationship with the senior citizens, getting to know them and being attentive to their specific ways of life, whilst still promoting small lifestyle changes that are in accordance with Danish public-health objectives. Some older people decline all invitations to become more active whilst others accept the promise of more positive subjectivities offered through achieving active ageing; they may even start to yearn for activity. In this sense, the activeageing scheme seems to be fashioning new dispositions and aspirations. The elderly also learn to talk about - and gradually seem to adopt - a pro-active relationship to their bodies. But on the other hand, the municipal interest in their well-being sometimes seems to create a sense that the older citizens are held responsible for any further decline if they do not partake in the activities mentioned or offered.

The excerpts from our fieldwork are on a small scale, but they nevertheless illustrate that the PHV is a site where the "naturalness" of the embodied nature of growing older is negotiated. PHVs work as a way to train the senses: out of the practice of health promotion, a new sensibility towards the inactive body may be born as a new experience as this preventive effort comprises educative aspects. The personal meeting between a home-visitor from the municipality, the preventive staff and an older citizen is one situation where the health message is effectively disseminated, and the ability and desire of the older citizen to engage in physical activities is negotiated, and shaped more or less successfully. Initially, Denmark's active-ageing scheme was intended to combat the social exclusion of older people by fostering their active participation in society. 
International Journal of Ageing and Later Life

We found that the logic of care used in PHVs incorporates a process of learning to age healthily, learning to manage life with a loss of functionality, learning to cope with illnesses and pain, learning to sense wellbeing, learning to care for oneself, and so forth. Essentially, the preventive visit is about promoting skills of self-care and self-awareness so that an elderly person can learn to enjoy life. And the means to properly monitor oneself involve numerous techniques that constitute a continuous exercise, a practice of the self. ${ }^{6}$ The instructions and negotiations that take place during a home visit reflect dilemmas though: How often does an older person have to be active, for how long and by using what kinds of exercise? How does one take care of the body?

This local Danish example may be seen as part of a larger trend within the context of the European Union and its Active Ageing programs. As a new target user-group for prevention, the elderly are enrolled in the biopolitical aspiration of the active-ageing paradigm. This enrolment process may partially occur through home visits and take the form of "a logic of care" (Mol 2008) and even involve elements of discipline and control. Hence, it makes sense to view the rationalities and technologies of the PHV as a strategic space for "biopolitics"; a possible space for new forms of self-perception and experience of people's bodies. The meaning of active ageing is negotiated in practice among individuals in relation to the meanings or ideologies are always already present in our societal framework, and many older people learn to recognise and embrace the potential of longevity through daily acts of walking and exercising. More studies with the same theoretical anchoring may develop this tradition of scholarship in a direction that gives more attention to the affective issues at play in accounts of the biopolitical, for example, address the problem of experience in order to perceive biopolitics as a historically specific formation of experience and embodiment.

\footnotetext{
${ }^{6}$ Foucault defines "practices of the self" as those reflective and voluntary practices by which people set themselves rules of conduct, and seek to transform themselves, to change themselves and their being that carries certain aesthetic and cultural values.
} 


\section{New perceptions of ageing}

Scientific research as well as direct engagement with older people in preventive health interventions and policy programmes related to active and independent ageing may be transforming ageing so it is no longer regarded or experienced as inevitable or immutable; rather as a malleable process. I tentatively suggest that preventive health visits play an important role in this because it reflects an attempt to shape acceptable forms of ageing whilst encouraging older adults to self-monitor their own success by conforming to the new healthy-ageing paradigm. In addition to preventing functional decline, the health advisors seek to meet and form the desires of older citizens. Thus, health promotion and preventive interventions are a way to manage or govern, yet they are simultaneously voluntary and productive.

The results from this study cannot be used to determine the extent to which people in general who are now old have actually appropriated the discourses about activity. Further research along these lines will add to our knowledge about how people manage their own biological existence as they age, in dialogue with or in protest against the discursive medical regimes in modern society. The current medical model focuses on disease, values, secondary prevention, and seeks to reduce mortality and morbidity as outcomes. Health visitors use other models, which instead value primary prevention and focus on goals such as empowerment, autonomy, independent decision-making, improved self-esteem and self-confidence - outcomes that are far more difficult to measure than mortality and morbidity. Nonetheless, physical activity as an ideal of life - as well as a way of life seems to be gaining an ever-greater foothold in the everyday lives of the people who comprise ageing populations in our contemporary society.

\section{Acknowledgements}

The research for this article was supported by a generous donation from the Nordea Foundation to the Centre for Healthy Ageing at the University of Copenhagen, Denmark. It was carried out with the assistance from two research assistants, Lise Lunding and Liv Groennow. The author would like to thank anonymous referees for their helpful comments. Thanks also goes to her research group at the Centre for Healthy Aging, University of 
International Journal of Ageing and Later Life

Copenhagen, and to the participants in our panel "Performativity and the Moral Imperatives of Healthy Ageing" at the THEORIZING AGE Conference at Maastricht University, the Netherlands, held 6-8 October 2011.

\section{Corresponding Author}

Lene Otto, Department of Ethnology and Center for Healthy Ageing, University of Copenhagen, Njalsgade 80, DK-2300 Copenhagen, Denmark. Email: lotto@hum.ku.dk

\section{References}

AgeForum. (2009). Older People and Preventive Home Visits. Copenhagen. Available on http://www.aeldreforum.dk/ageforum/reports-fromageforum/other-reports/copy_of_older-people-and-preventive-homevisits (Accessed: February 12, 2013).

Althusser, L. (1970). Ideology and ideological state apparatuses. In Lenin and Philosophy and Other Essays. Monthly Review Press 1971. Available on http://www.marxists.org/reference/archive/althusser/ 1970/ideology.htm (Accessed: November 8, 2012).

Biggs, S. (2001). Toward critical narrativity: Stories of aging in contemporary social policy. Journal of Aging Studies 15(1): 303-316.

Blencowe, C. (2012). Biopolitical Experience: Foucault, Power and Positive Critique. Basingstoke, UK: Palgrave Macmillan.

Danish Elderly Commission. (1980). Changes of Age - the Prerequisites of the Elder Policy. Copenhagen: Danish Elderly Commission. Report No. 1.

Davey, J. A. (2002). Active ageing and education in mid and later life. Ageing \& Society 22: 95-113.

Fine, M. \& Glendinning, C. (2005). Dependence, independence or interdependence? Revisiting the concepts of 'care' and 'dependency'. Ageing $\mathcal{E}$ Society 25(4): 601-621.

Foucault, M. (1976) 1998. The History of Sexuality Vol. 1: The Will to Knowledge. London: Penguin.

Hendriksen, C. (1989). Rødovreprojektet: Forebyggende interventionsbesøg hos gamle mennesker [The Rødovre Project: Preventive Intervention Visits to Older People]. Privately published PhD Dissertation. Copenhagen: University of Copenhagen. 
Holstein, M. \& Minkler, M. (2007). Critical gerontology: Reflections for the 21st century. In M. Bernard \& T. Scharf (eds.), Critical Perspectives on Ageing Societies. Bristol, UK: Policy Press.

Katz, S. (1996). Disciplining Old Age: The Formation of Gerontological Knowledge. Charlottesville, VA: University of Virginia Press.

Katz, S. (2000). Busy bodies: Activity, ageing and the management of the everyday life. Journal of Ageing Studies 14(2): 135-152.

Lewinter, M. (2008). Aldring. Sociologisk Set. Copenhagen: Samfundslitteratur.

Mol, A. (2008). The Logic of Care. Health and the Problem of Health Care. London: Routledge.

Mol, A. (2010). Care and its values. Good food in the nursing home. In A. Mol, I Moser \& J. Pols (eds.), Care in Practice: On Tinkering in Clinics, Homes and Farms (pp. 214-234). Bielefeld: Transcript Verlag.

Moody, H. R. (2001). Productive ageing and the ideology of old age. In N. Morrow-Howell, J. Hinterlong \& M. V. Sherraden (eds.), Productive Ageing (pp. 175-194). Baltimore, MD: John Hopkins University Press.

Neilson, B. (2006). Anti-ageing cultures, biopolitics and globalisation. Cultural Studies Review 12: 149-164.

O'Leary, T. (2008). Foucault, experience, literature. Foucault Studies no. 5; 5-25. Available on http://cjas.dk/index.php/foucault-studies/article/ view/1407/1510 (Accessed: May 10, 2012).

Pilgaard, M. (2007). Danskernes motions- og sportsvaner 2007 - nøgletal og tendenser. Copenhagen: Idrættens analyseinstitut.

Powell, J. L. \& Biggs, S. (2000). Managing old age: The disciplinary web of power, surveillance and normalization. Journal of Aging \& Identity 5(1): 3-13.

Powell, J. L. \& Wahidin, A. (eds.). (2006). Foucault and Aging. New York: Nova Science Publishers Inc.

Rostgaard, T. (2011). Livindhome: Living Independently at Home: Reforms in Home Care in 9 European Countries. Copenhagen: SFI the Danish National Centre for Social Research.

Stott, M. (1981). Ageing for Beginners. Oxford: Blackwell.

Vass, M. (2010). Prevention of Functional Decline in Older People: The Danish Randomized Intervention Trial on Preventive Home Visits. PhD Dissertation. The Faculty of Health and Medical Sciences at the University of Copenhagen. Copenhagen: University of Copenhagen. 